\title{
Management of Giant Hydatid Liver Disease: A Case Report and Review of Literature
}

\author{
Volkan Sarper Erikci ${ }^{1 *}$, Merve Dilara Oney ${ }^{1}$, Tuna Altundag ${ }^{1}$, Emre Divarci $^{2}$, Orkan Ergun ${ }^{2}$, \\ Fatih Tekin $^{3}$, Gokhan Koyluoglu ${ }^{4}$ \\ ${ }^{1}$ Department of Pediatric Surgery, İzmir Tepecik Training Hospital, Saglık Bilimleri University, Turkey \\ ${ }^{2}$ Department of Pediatric Surgery, Ege University, Izmir, Turkey \\ ${ }^{3}$ Department of Gastroenterology, Ege University, Izmir, Turkey \\ ${ }^{4}$ Department of Pediatric Surgery, KÇU, Izmir, Turkey
}

"Corresponding Author: Volkan Sarper Erikci, Associate Professor of Pediatric Surgery, Department of Pediatric Surgery, İzmir Tepecik Training Hospital Sagllk Bilimleri University, Izmir, Turkey, E-mail: verikci@yahoo.com

\begin{abstract}
Hydatidosis which is caused by the larval form of Echinococcus granulosus is a widely endemic disease in many parts of the world. According to the Ministry of Health database, there are 14000 cases recorded from 2001 to 2005 in Turkey. The liver is involved in 50\%-70\% of cases. A 14-year-old boy with a giant echinococcal cyst occupying 2/3 of the right lobe of the liver was surgically treated using polyglicolic acid sheet (PGA). Endoscopic retrograde cholangiopancreatography (ERCP) with sphincterotomy was performed for persistent bile leakage during postoperative period. Biliary fistula healed 2 days following sphincterotomy. In this report, our case is presented to adress current information about management of huge liver echinococcosis in the light of relevant literature.
\end{abstract}

Keywords: Hydatidosis, Ultrasonography, Cystotomy

\section{INTRODUCTION}

Hydatidosis which is caused by the larval form of Echinococcus granulosus is a widely endemic disease in many parts of the world. According to the Ministry of Health database, there are 14000 cases recorded from 2001 to 2005 in Turkey (1). The liver is involved in $50 \%-70 \%$ of cases $(2,3-$ 5). A 14-year-old boy with a giant echinococcal cyst occupying $2 / 3$ of the right lobe of the liver was surgically treated using polyglicolic acid sheet (PGA). Endoscopic retrograde cholangiopancreatography (ERCP) with sphincterotomy was performed for persistent bile leakage during postoperative period. Biliary fistula healed 2 days following sphincterotomy. In this report, our case is presented to adress current information about management of huge liver echinococcosis in the light of relevant literature.

\section{CASE}

A 14-year-old boy was admitted to our clinic with a shoulder pain and epigastric discomfort. A large palpable mass was found in the upper abdomen upon clinical examination. Ultrasonography (US) and computed tomography (CT) scan showed a giant cystic mass occupying nearly $2 / 3$ of right liver lobe accompanying a solidified satellite cyst at the inferior margin of the right lobe (Figure 1). CT clearly delineated reactive layer (pericystic wall) containing fibrous tissue and calcifications. No other organs were involved by the disease. An indirect hemagglutination test was used for the serological confirmation of the diagnosis. A laparotomy under general anesthesia was performed using a liberal subcostal incision. A giant cystic mass of $15 \mathrm{~cm}$ in diameter occupying most of the right lobe of the liver was found. The mass pushed dome of the right diaphragm upwards and liver downwards. Packs enriched with hypertonic saline $(20 \% \mathrm{NaCl})$ for prevention of dissemination of disease were used for isolation. A volume of $1050 \mathrm{ml}$ clear fluid was aspirated and scolocidal solution $(20 \%$ $\mathrm{NaCl}$ ) was injected into the cavity. After evacuating the cyst contents and cystotomy the entire endocyst comprising both the inner 
germinal and outer chitinous layers was totally extracted from the ectocyst of the surrounding liver parenchyme (Figure 2). Visible biliary orifices were sutured with $3 / 0$ polyglicolic acid sutures. In order to avoid any biliary fistulas that may happen to occur during postoperative period, a polyglicolic acid (PGA) sheet (Neoveil, Gunze, Osaka, Japan) was also applied to the surfaces of sutured biliary orifices in the endocyst using fibrin glue (Figure 3 ). The large cavity after enucleation was filled with omentum to prevent collection of fluid and abscess formation and a capitonnage was added to the procedure at the end of the surgical procedure (Figure 4). An external catheter with multiple side-holes at the tip was also inserted into the bottom of the residual cavity for drainage. Bile leakage of $150 \mathrm{ml} /$ day from the external catheter did not decrease during postoperative period despite medical treatment including total parenteral nutrition, systemic octreotide usage and an ERCP with sphincterotomy was performed on the $28^{\text {th }}$ postoperative day for intractable bile leakage. Bile leakage dramatically decreased after sphincterotomy and eventually stopped 2 days after ERCP and the drainage catheter was removed. The patient is now well with no symptoms of disease and receiving regular dose of $10 \mathrm{mg} / \mathrm{kg}$ of benzimidazole compounds (albendazole/mebendazole)

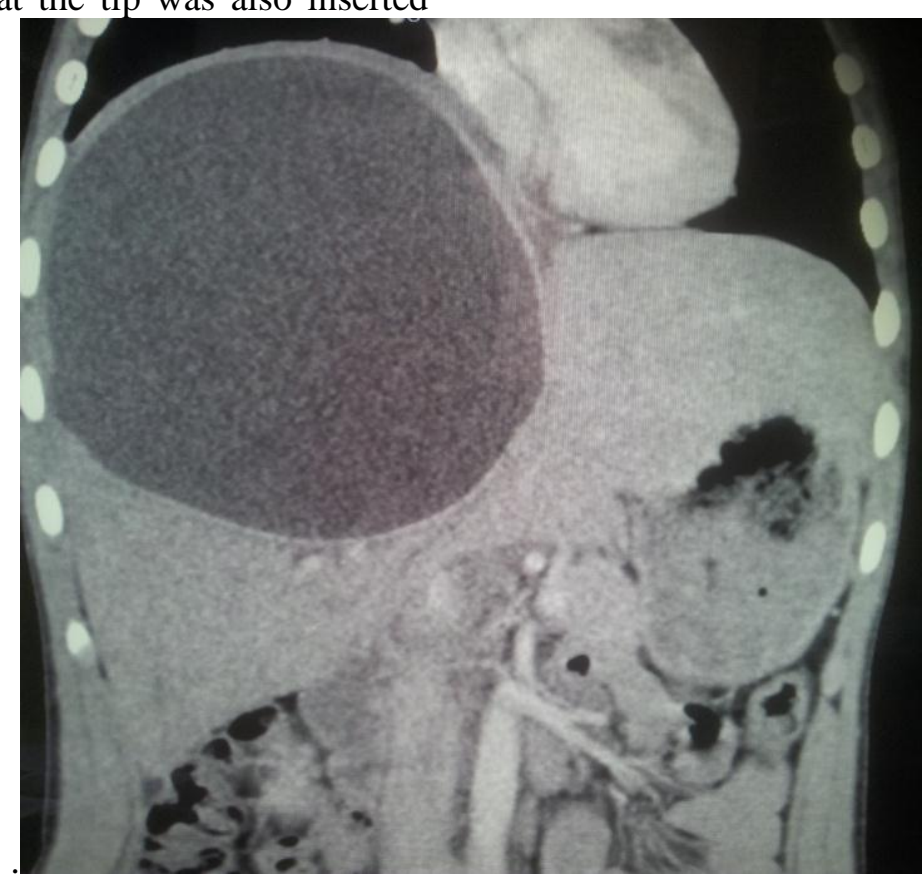

Figure1. CT showing the giant cyst $(15 \mathrm{~cm})$ occupying most of the right lobe of the liver.

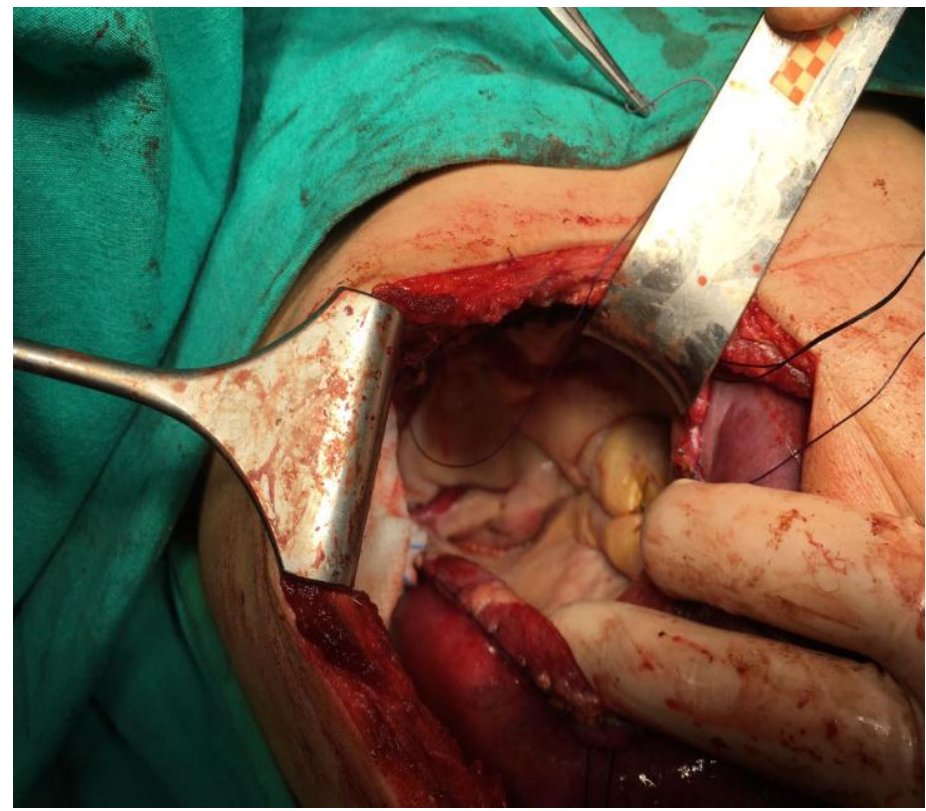

Figure2. Operative view of opened cyst. Note the entire endocyst was totally extracted. 


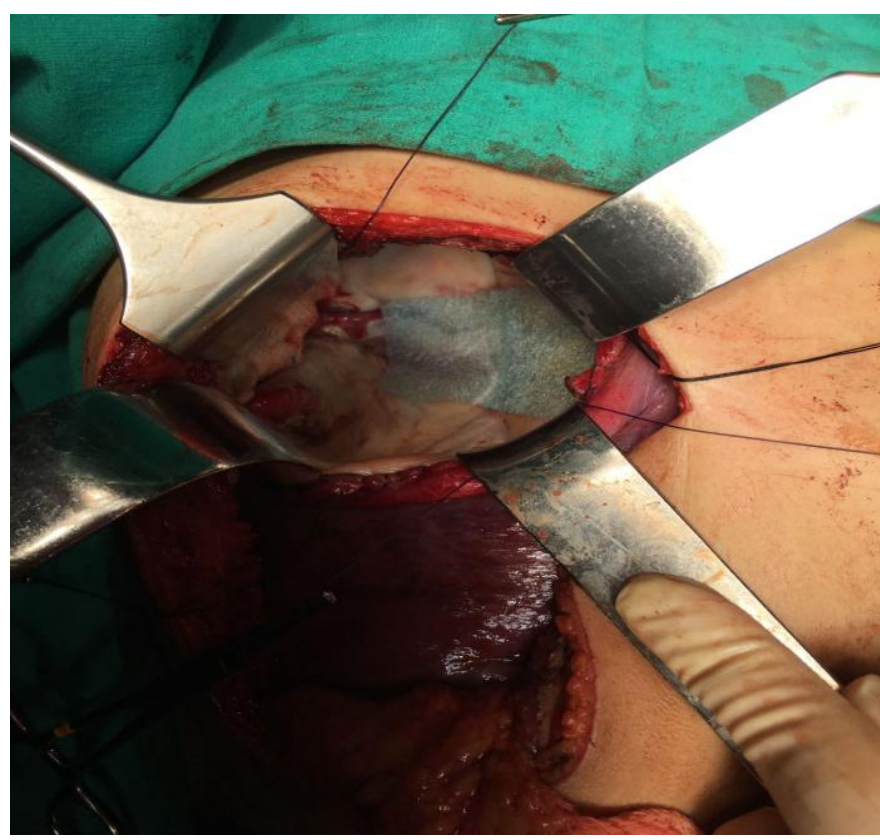

Figure3. Operative view. note partial cyst wall excision was performed and PGA sheet inserted into the cyst cavity.

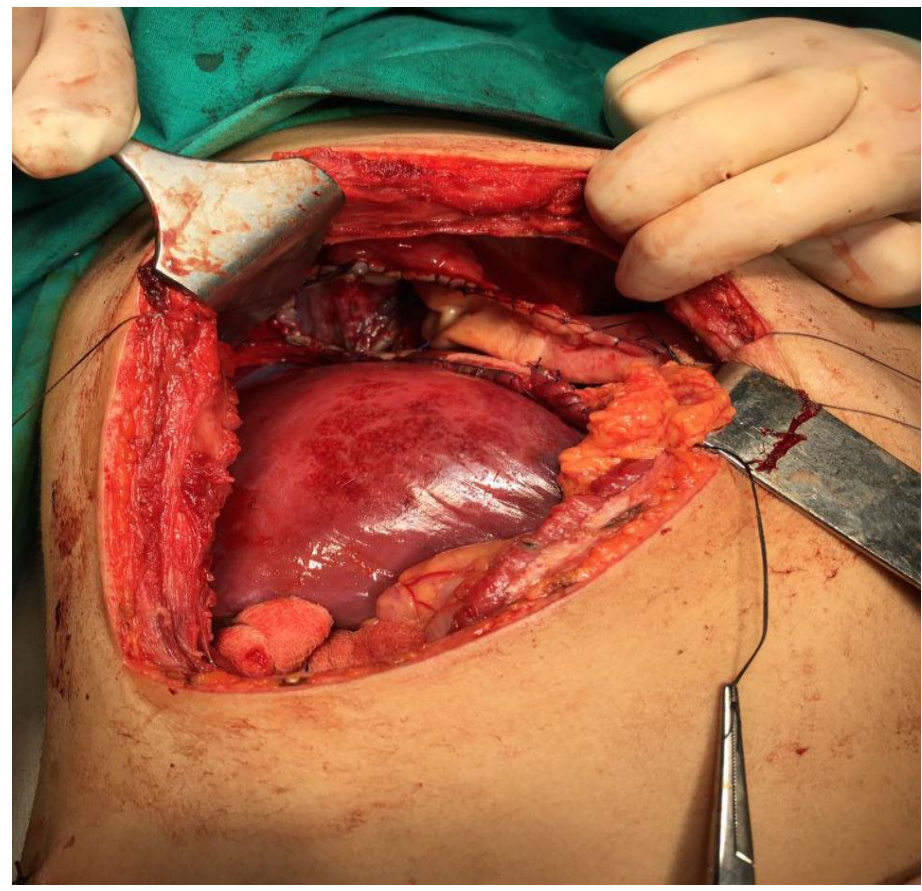

Figure4. Operative view. The large cavity after enucleation was filled with omentum and capitonnage was completed.

\section{DISCUSSION}

Treatment of hydatid cyst has not changed much over the years and surgery remains the cornerstone of the management of hepatic hydatid disease (6-10). Choices of treatment modalities can be divided into two basic groups: radical or conservative. Hepatectomy and pericystectomy are radical operations and carry a certain perioperative risk. But it is stated that biliary leakage and recurrence are rare in radical surgical interventions (11-13). Consevative methods including partial cystectomy with external drainage, omentoplasty and capitonnage are easier to perform but carry a high incidence of postoperative biliary leakage and recurrence $(4,13)$. The PAIR procedure that is also a conservative treatment modality of liver hydatid disease refers to puncture of the cyst, aspiration, injection of scolocidal agent into the cyst and reaspiration. It has been proposed as an alternative approach to surgery. Conservative surgical approach including cystotomy, evacuation of the cyst and its contents, suture ligation of biliary fistulas, omentoplasty and capitonnage was performed in our case. Besides 
PGA was applied to the biliary leakage surfaces in the endocyst after suture ligation of the fistulas in order to prevent subsequent fistula formation.

Although hydatid cyst of $10 \mathrm{~cm}$ or greater in diameter are called "giant" cysts traditionally there are no uniformly accepted criteria that define "giant" liver hydatid disease (14). Only a few cases of huge liver HD have been reported so far and these are adult patients (15-18). Literature on this issue is more scarce in pediatric patients (19). Presence of large cysts in children can be more dangerous than in adults as they may produce pressure effect to nearby structures and destroy the parenchyme of the developing organ. With a diameter of $15 \mathrm{~cm}$, the cyst in our case was accepted to be giant and timely-agressive surgical treatment was performed.

Biliary fistulas are the most common morbidity following hydatid liver surgery with an incidence of $13 \%-37 \%(20,21-25)$. It is defined as any drain output consistent with a biliary appearance with a high bilirubin count. Intracystic pressure is $30-80 \mathrm{cmH}_{2} \mathrm{O}(24-26)$. According to the LaPlace Law, expansion of the cyst further increases the intracystic pressure therefore flow is toward the biliary system. Once the cyst has been drained pressure dynamics reversed and bile flows into the residual cavity rather than through the biliary system via papilla of Vater (27). Despite measures were taken for the prevention of future probable biliary leakage in our case during the surgical intervention including suture ligation and PGA application on the surface of probable leakage sites in the endocyst, biliary leakage unfortunately occured in our patient during postopertaive period.

Although there are reports stating that all the biliary fistulas close spontaneously after surgical treatment of liver HD, they persist in 4\%-27.5\% of cases $(28,29)$. Endoscopic sphincterotomy has been proposed in biliary fistula of more than 3 weeks' duration or with output exceeding 300 $\mathrm{ml} /$ day but unfortunately these reports come from adult series $(4,30)$. Literature on this subject with regard to children is scarce (28). It was demonstrated that a postoperative biliary drainage volume $<102 \mathrm{ml}$ to be the only predictor of spontaneous closure of biliary fistula following liver HD surgery (31). Nevertheless, once conservative measures to control the post-surgical biliary leakage in children with huge liver hydatid disease are inadequate, the clinician dealing with these children should not hesitate to perform ERCP and sphincterotomy.

In conclusion, management of giant liver hydatid disease may constitute a great challenge to attending surgeon. Despite preventive measures, if postoperative biliary fistula develops after surgical intervention it should first be treated by conservative methods. If the bile leakage persists then the endoscopic procedures including ERCP and sphincterotomy becomes necessity for treatment of these patients.

\section{REFERENCES}

[1] Yazar S, Ozkan AT, Hökelek M, Polat E, Yilmaz E, et al. Cystic echinococcosis in Turkey from 2001-2005. Turkiye Parazitol Derg 2008; 32: 208-220

[2] Sayek I, Yalin R, Sanac Y. Surgical treatment of hydatid disease of the liver. Arch Surg 1980; 115: $847-50$

[3] Akkiz H, Akinoglu A, Çolakoglu S, et al. Endoscopic management of biliary hydatid disease. Can J Surg 1996; 39: 287-292

[4] Skroubis G, Vagianos C, Polydorou A, et al. Significance of bile leaks complicating conservative surgery for liver hydatidosis. World J Surg 2002; 26: 704-8

[5] Al Karawi MA, Yasawy MI, El Skiekh Mohamed AR. Endoscopic management of biliary hydatid disease: report of six cases. Endoscopy 1991; 23: 278-81

[6] Symeonidis T, Pavlidis T, Baltatzis M, Ballas K, Psarras K, Marakis G, Sakantamis A. Complicated liver echinococcosis: 30 years of experience from an endemic area. Scand J Surg 2013; 102: 171-7

[7] Voros D, Katserelias D, Polymeneas G, Polydorou A, Pistiolis I, Kalovidouris A, Gouliamos A. Treatment of hydatid liver disease. Surg Infect (Larchmt) 2007; 8: 621-7

[8] Halezeroglu S, Okur E, Tanyü MO. Surgical management for hydatid disease. Thorac Surg Clin 2012; 22: 375-85

[9] Benkabbou A, Sauadka A, Serji B, Hachim H, Mohsine R, Ifrine L, Belkouchi A, ElMalki HO. Changing paradigms in the surgical management of cystic liver hydatidosis improve the postopertive outcomes. Surgery 2016; 159: 1170-80

[10] Gomez I, Gavara C, Lopez-Andujar R, Belda Ibanez I, Ramia Angel JM, Moya Herraiz A, Orbis Castellanos F, Pereja Ibars E, San Juan Rodriguez F. Review of the treatment of liver hydatid cysts. World J Gastroenterol 2015; 21: 124-31 
[11] Giordano G, Angrisano A, Palazzo P, et al. Surgical treatment of hydatid cyst of the liver: pericystectomy or resection. Personal experience. Int J Surg Sci 1996; 6: 113-7

[12] Moreno Gonzalez E, Rico Selas P, Martinez B, et al. Results of surgical treatment of hepatic hydatidosis: current therapeutic modifications. World J Surg 1991; 15: 254-63

[13] Kayaalp C, Sengul N, Akoglu M. Importance of cyst content in hydatid liver surgery. Arch Surg 2002; 137: 159-63

[14] Usluer O, Ceylan KC, Kaya S, Sevinc S, Gursoy S. Surgical management of pulmonary hydatid cyst. Texas Heart Institute Journal 2010; 37: 429-34

[15] Bonfrate L, Giuliante F, Palasciano JT, Lamont P. Unexpected discovery of massive liver echinococcosis. A clinical, morphological and functional diagnosis. Ann Hepatol 2013; 12: 634-41

[16] Salemis NS. Giant hydatid liver cyst: management of residual cavity. Ann Hepatol 2003; $7:$ 174-6

[17] Ettorre GM, Vennarecci G, Santoro R, Laurenzi A, Ceribelli C, DiCintio A, et al. Giant hydatid cyst of the liver with a retroperitoneal growth: a case report. J Med Case Rep 2012; 6: 298

[18] Sahin DA, Kusaslan R, Sahin O, Dilek ON. Huge hydatid cysts that arise from the liver growing exophytically. Can J Surg 2007; 50: 301-3

[19] Goyal VD, Sood S, Rana S, Pahwa S. Singlestage management of large pulmonary and hepatic hydatid cysts in pediatric age group: report of two cases. Lung India 2014; 31(3): 267-9

[20] Langer JC, Rose DB, Keystone JS, et al. Diagnosis and management of hydatid disease of the liver. Ann Surg 1984; 199: 412-7

[21] Kayaalp C, Bostanc1 B, Yol S, et al. Distribution of hydatid cysts into the liver with reference to cystobiliary communications and cavity-related complications. Am J Surg 2003; 185: $175-9$
[22] Alper A, Ariogul O, Emre A, et al. Choledocoduodenostomy for intrabiliary rupture of hydatid cysts of liver. Br J Surg 1987; 74: 243-5

[23] Bedirli A, Sakrak O, Sozuer EM, et al. Surgical management of spontaneous intrabiliary rupture of hydatid liver cysts. Surg Today 2002; 32: 594-7

[24] Ozaslan E, Bayraktar Y. Endoscopic therapy in the management of hepatobiliary hydatid disease. J Clin Gastroenterol 2002; 35: 160-74

[25] Milicevic H. Hydatid disease. In: Blumgart L, Fong Y, editors. Surgery of the liver and biliary tract, 2nd ed. Philadelphia: WB Saunders Company; 2000. p.1167-204

[26] Yalın R, Aktan AÖ, Yegen C, et al. Significance of intracystic pressure in abdominal hydatid disease. Br J Surg 1992; 79: 1182-3

[27] Vignote ML, Mino G, de la Mara, et al. Endoscopic sphincterotomy in hepatic hydatid disase open to the biliary tree. Br J Surg 1990; 77: $30-1$

[28] Tiryaki HT, Şenel E, Akbıyık F, Mambet E, Livanelioğlu Z, Atayurt HF. Is the biliary complication really seen lesser in children with hydatid liver disease? Turkish J Pediatr Dis 2009; 3(4): 34-9

[29] Dolay K, Akçakaya A, Soybir G, et al. Endoscopic sphincterotomy in the management of postoperative biliary fistula. A complication of hepatic hydatid disease. Surg Endosc 2002; 16: $985-8$

[30] Gharbi HA, Hassine W, Brauner MW, et al. Ultrasound examination of the hydatic liver. Radiology 1981; 139: 459-63

[31] Zeybek N, Dede H, Balci D, Coşkun AK, Ozerhan İH, Peker S, Peker Y. Biliary fistula after treatment for hydatid disease of the liver: when to intervene. World J Gastroenterol 2013; 19(3): 355-61.

Citation: Volkan Sarper Erikci, Merve Dilara Oney, Tuna Altundag, Emre Divarci, Orkan Ergun, Fatih Tekin, et al. Management of Giant Hydatid Liver Disease: A Case Report and Review of Literature. ARC Journal of Pediatrics. 2017; 3(1):9-13. doi:dx.doi.org/10.20431/2455-5711.0301003.

Copyright: (c) 2017 Authors. This is an open-access article distributed under the terms of the Creative Commons Attribution License, which permits unrestricted use, distribution, and reproduction in any 